\title{
Does climate change influence the frequency of large rock slope failures?
}

\section{Other Conference Item}

Author(s):

Loew, Simon (iD) Buehler, Nora; Aaron, Jordan

Publication date:

2020

Permanent link:

https://doi.org/10.3929/ethz-b-000462261

Rights / license:

Creative Commons Attribution 4.0 International

Originally published in:

EGUsphere, https://doi.org/10.5194/egusphere-egu2020-7361 
EGU2020-7361

https://doi.org/10.5194/egusphere-egu2020-7361

EGU General Assembly 2020

(c) Author(s) 2021. This work is distributed under

the Creative Commons Attribution 4.0 License.

\section{Does climate change influence the frequency of large rock slope failures?}

Simon Loew, Nora Buehler, and Jordan Aaron

Department of Earth Sciences, ETH Zurich, Zurich, Switzerland (simon.loew@erdw.ethz.ch)

A large number of scientific contributions (e.g. BAFU 2017, Speicher 2017, Phillips et al. 2017, Ravanel et al. 2017, Haque et al. 2016) have suggested that many recent rock slope failures in the European Alps have been triggered by climate warming. For example, Huggel et al. 2012 and Fischer et al. 2012 could show that rock fall frequencies above 2000 masl increased significantly since 1990 at regional (Swiss Alps and adjacent areas) and local (Mont Blanc) scale, based on 52 events larger than $1000 \mathrm{~m}^{3}$ (PERMOS data base) covering the period 1900-2010. This increase in frequency could be correlated with a significant departure of mean annual temperature from the 1960-1990 average, based on a dataset describing conditions in Switzerland. Paranunzio et al. 2016 systematically studied the climatic conditions and anomalies occurring before 41 rock fall events in the Italian Alps with volumes of several hundred to several million $\mathrm{m}^{3}$. They show that positive and negative temperature anomalies triggered the majority of analysed rock fall events in a complex manner, but that melting of permafrost was clearly not the only rock fall trigger.

However, there have been no studies which systematically investigate changes in the frequency of rock fall events based on complete inventories covering a large range of rock fall volumes. To fill this gap, we have generated a new database for rapid rock slope failures in the Swiss Alps covering events larger than $100^{\prime} 000 \mathrm{~m}^{3}$ (Bühler 2019, BSc Thesis ETH 2019). This catalogue covers the period between 1700 and 2019 and includes 86 events with reliably estimated volume, date and location of occurrence, and pre-disposing factors (such as slope orientation, permafrost occurrence and geological setting). Volume-cumulative frequency plots of the events demonstrate completeness of the catalogue for all size classes, and significant changes in the ratios between large and small events through time.

An enhanced frequency of the volume class of $10^{5} \mathrm{~m}^{3}\left(100^{\prime} 000-999^{\prime} 000 \mathrm{~m}^{3}\right)$ is observed starting from 1940, predominantly occurring in permafrost areas and elevations ranging between 2800 and 3200 masl. This increasing frequency signal with time disappears for increasing volumes beyond a magnitude of about $400^{\prime} 000 \mathrm{~m}^{3}$ and is clearly absent for very large rock slope failure of millions to tens of millions of $\mathrm{m}^{3}$.

The volume dependence of climate sensitivity can be physically explained, as larger volume slope failures tend to have deeper failure surfaces. Typical failure depth for multi-million $\mathrm{m}^{3}$ slope failures in crystalline rocks are up to a few 100 meters, and beyond the depth of Alpine permafrost. Direct impacts of surface temperature changes on permafrost are mainly manifested 
through a minor thickening of the active layer, typically ranging between 1 and 10 meters, but indirect effects at the depth range of decameters (i.e. the depth of failure surfaces for events of the $10^{5} \mathrm{~m}^{3}$ class) have been assessed and demonstrated in a large number of studies. 